\title{
Use of acoustic telemetry for spatial management of southern calamary Sepioteuthis australis, a highly mobile inshore squid species
}

\author{
Gretta T. Pecl ${ }^{1, *}$, Sean R. Tracey ${ }^{1}$, Jayson M. Semmens ${ }^{1}$, George D. Jackson ${ }^{2}$ \\ ${ }^{1}$ Tasmanian Aquaculture \& Fisheries Institute, Private Bag 49, and ${ }^{2}$ Institute of Antarctic \& Southern Ocean Studies, \\ Private Bag 77, University of Tasmania, 7001 Tasmania, Australia
}

ABSTRACT: The use of temporal and/or spatial fishing exclusions is a common approach in managing impacts of squid fisheries targeting spawning aggregations, although there are limited data for assessing closed areas as a management tool. We evaluated the degree of protection that 2 closed areas were providing to individual spawning Sepioteuthis australis and assessed the extent of exchange between these coastal regions, separated by only 25 to $32 \mathrm{~km}$. VR2 acoustic receivers were placed along the boundaries of closed areas on the east coast of Tasmania, Australia, across smaller bays within these areas, and on individual seagrass beds. Over 77000 detection events were obtained from 46 individuals over durations of up to $129 \mathrm{~d}$, demonstrating that individuals spawn over several months, traveling $100 \mathrm{~s}$ of $\mathrm{km}$ within the spawning areas during this time. Squid were detected at closed area boundaries; however, most were detected again on other receivers within the closed area, indicating that although squid had moved within boundary vicinities, they had not actually left the protected area. Closures of critical spawning regions during times of heightened reproductive activity will therefore achieve the desired effect of protecting spawners and will allow for egglaying. Clearly, inshore squid species can be highly mobile during an extended spawning phase and any assessment of the management benefits of closed areas needs to explicitly consider the temporal and spatial scales of the closed area in question.

KEY WORDS: Movement · Closed areas · Squid fisheries - Spawning behavior · Tracking $\cdot$ Reproductive effort $\cdot$ Spawning duration

Resale or republication not permitted without written consent of the publisher

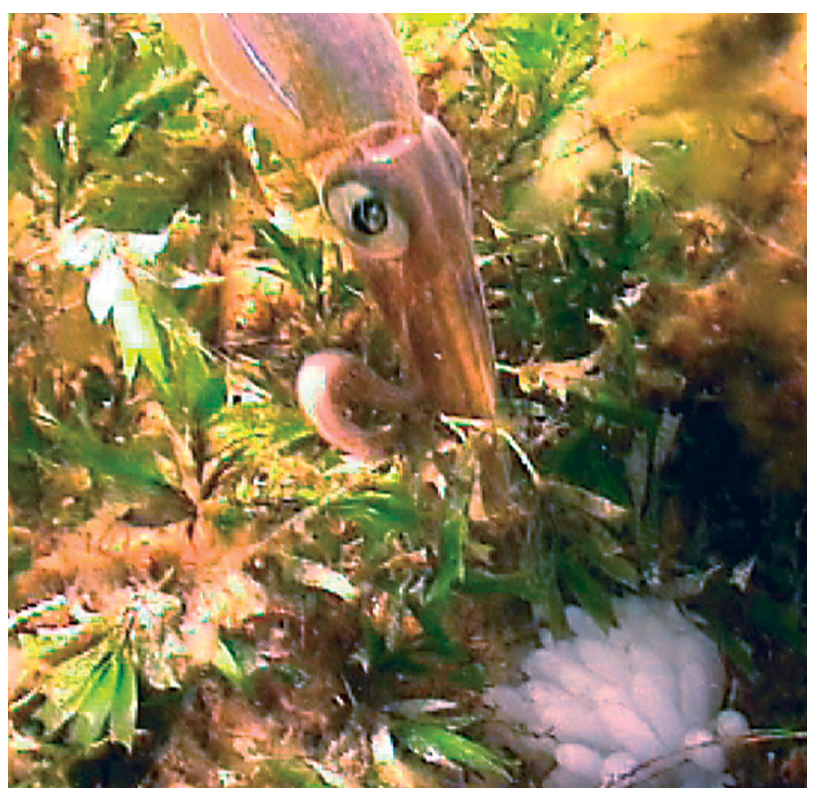

There are few data for assessment of the efficacy of closures in the management of squid fisheries. Pecl and co-workers recorded movements of sexually mature squid for several months, providing evidence of an extended spawning period that constitutes 20 to $40 \%$ of their lifespan. Tagged squid traveled $100 \mathrm{~s}$ of $\mathrm{km}$ while spawning, but they stayed within the closed areas.

Photo: Troy Jantzen

\section{INTRODUCTION}

Understanding the temporal and spatial utilization of habitats by target species is an important step in evaluating and protecting fishery resources (Arendt et al. 2001). Information concerning the amount of space a 
species utilizes, how long individuals remain within that space, and how often they leave and return, are critical to implementing effective closed areas and protecting spawning stock (Heupel et al. 2006). Additionally, the benefits of areas closed to fishing are highly dependent on the scale and rate of movement of key species in relation to the size of the closed area (Zeller 1997, Egli \& Babcock 2004). The spatial and temporal scale of closures must incorporate spawning migrations or movements and not just the spawning site itself, as both movement to/from spawning sites and spawning itself represent points at which the stock is accessible (Fulton et al. 1999). Southern calamary Sepioteuthis australis is a short-lived (Pecl 2004) and multiple-spawning (Pecl 2001) inshore loliginid squid that aggregates over shallow inshore seagrass beds in spring and summer to spawn, although low level spawning may take place throughout most of the year. This study employed the use of a large network of submerged acoustic receivers to assess the movements of acoustically tagged sexually mature southern calamary between and within the 2 main known spawning areas, which were both closed to commercial fishing during the 2003 spawning season.

As is the case with many squid fisheries (Augustyn \& Roel 1998, Hanlon 1998) the fishery for Sepioteuthis australis primarily targets spawning aggregations. The use of temporal and/or spatial fishing exclusions is a common approach to attempt to manage impacts of such fisheries (e.g. Loligo gahi in the Falkland Islands: Hatfield \& Des Clers 1998) and these are usually placed with the explicit aim of protecting spawning stock from fishing and allowing spawning to take place (Moltschaniwskyj et al. 2002). Protection of spawning capacity of the population is particularly crucial for short-lived species that depend on the current generation for recruitment of the next generation. Since 1999 short-term spatial closures of the commercial fishery for Sepioteuthis australis have been in place over either one or both of the main known spawning areas on the east coast of Tasmania - Great Oyster Bay and Mercury Passage - which are separated by only 25 to $32 \mathrm{~km}$. Closures in these key spawning areas have had different durations ( $2 \mathrm{wk}$ to $3 \mathrm{mo}$ ), frequencies ( 2 or 3 shorter closures vs. a single longer closure) and often boundaries (Moltschaniwskyj et al. 2002, Pecl et al. 2004).

Originally only Great Oyster Bay was periodically closed to commercial fishing; however, one of the outcomes of the original closure was a redistribution of fishing effort further south to Mercury Passage. High levels of catch and effort have subsequently persisted in Mercury Passage to the extent that the 2 areas are now of similar importance in terms of those parameters (Lyle et al. 2005), with both areas providing the vast majority of the Tasmanian annual catch for southern calamary. Since 2002 both areas have been periodically closed to commercial fishing; however, despite the close proximity of the 2 areas, the relationship between them in terms of movement and exchange of individuals, both prior to maturity and during the spawning season, is unresolved. Previous work in Great Oyster Bay suggests that waves of new individuals are entering the area throughout the spawning season (Jackson \& Pecl 2003). The origin of these individuals is unclear, but they could potentially be individuals moving northward from Mercury Passage. Additionally, although multiple spawning is now recognized to be common among loliginid squids (Moltschaniwskyj 1995, Maxwell \& Hanlon 2000, Hanlon et al. 2004) it has been difficult to assess the length of individual maturity in Sepioteuthis australis or any other species. Consequently, it is unknown how long spawning individuals are resident within the spawning regions, i.e. whether we are seeing many groups of short-term residents, or fewer groups of longer-term residents.

Here we used a system of submerged acoustic receivers to passively track squid movements, using a 'gate' or 'curtain' system to monitor movement across boundaries of closed areas and within smaller bays inside the closed areas, and isolated receivers to examine movement on specific spawning beds. The most promising current application of electronic tagging to fishery management is elucidation of habitat use (Sibert \& Nielsen 2000). Submerged independent single-channel acoustic receiver arrays have been used to examine movement within defined study regions (e.g. Heupel et al. 2004), as well as to monitor when individuals enter or exit specific areas (e.g. Comeau et al. 2002), with electronic tagging approaches providing detailed insights not previously possible (Heupel et al. 2006).

This study examined temporal and spatial movement patterns of southern calamary Sepioteuthis australis within a defined area of the east coast of Tasmania, Australia, in order to determine the extent to which closed areas meet management expectations in terms of providing protection to the spawning stock. Specifically, we were interested in detecting any movement and mixing or exchange of individuals between the 2 main spawning areas of Great Oyster Bay and Mercury Passage and assessing the degree of protection that the 2 closed areas provided during the spawning and closure period, i.e. determining the extent to which squid stayed within the boundaries of the closed areas. In addition to monitoring if and when individuals exited and returned to the closed area, we wished to define how individuals were using the smaller bays within the closed area and to estimate the residency of individual, sexually mature squid on the spawning 
grounds. An assessment of the time that mature individuals are actively moving within the spawning area will provide a good indication of how individuals are spatially and temporally distributing reproductive effort.

\section{MATERIALS AND METHODS}

Study site and acoustic receivers. The study was carried out on the east coast of Tasmania, Australia, in Great Oyster Bay and Mercury Passage (Fig. 1). Great

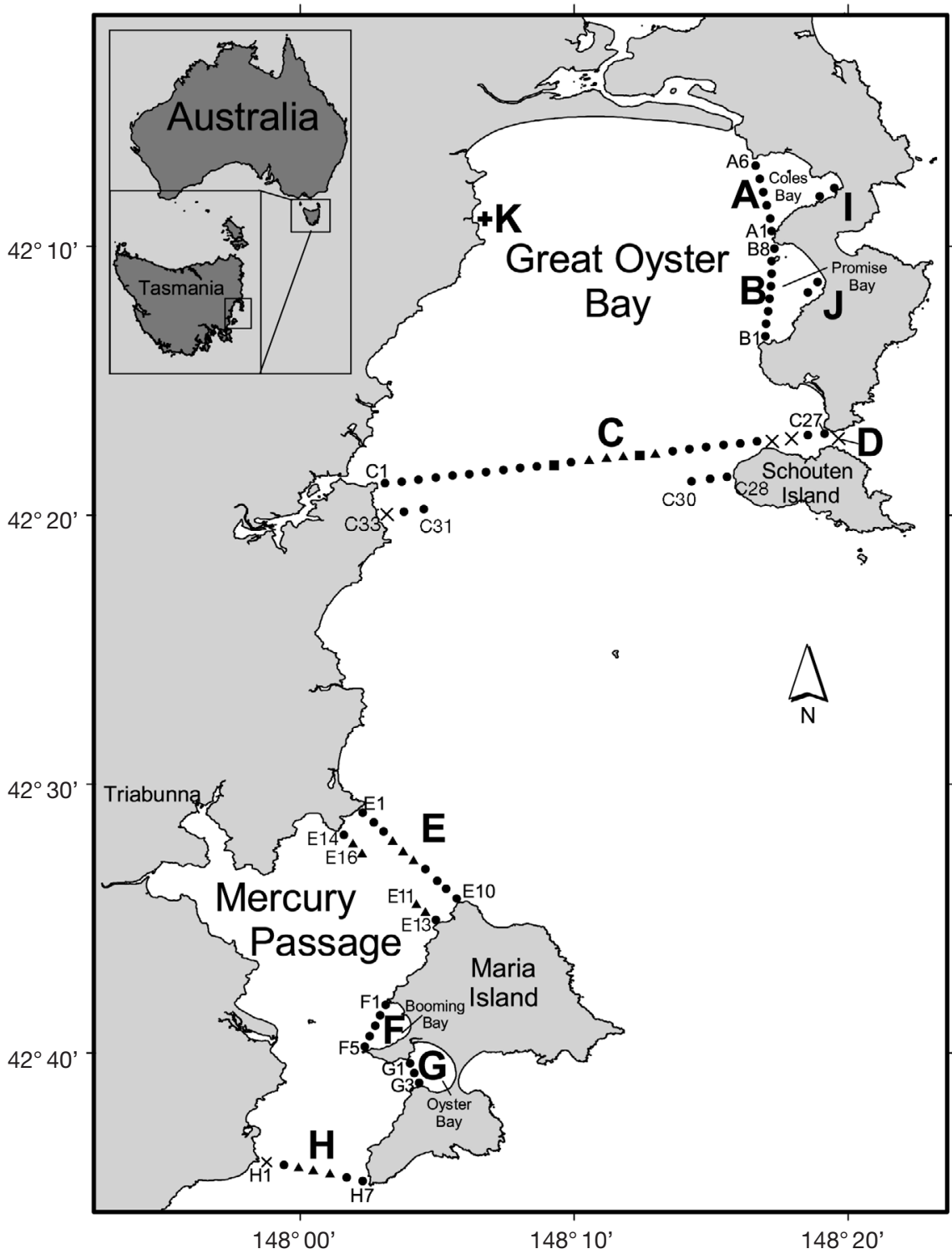

Fig. 1. East coast of Tasmania indicating placement of individual receivers within Great Oyster Bay and Mercury Passage, showing identification numbers of individual receivers. All receivers deployed on 22-24 July 2003, except + deployed on 9 October 2003. $\mathbf{\Delta}$ : receivers removed for another project on the 25th November

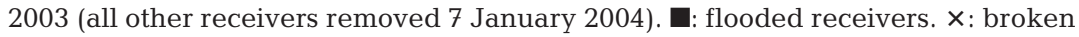
or missing receivers
Oyster Bay is a large shallow basin with a substrate primarily of sand with patchy seagrass beds (mainly located along the eastern shore) and occasional patches of rocky reef. The area of the bay is ca. $450 \mathrm{~km}^{2}$, mostly shallower than $20 \mathrm{~m}$, with the exception of the mouth of the bay where a ridge drops down to ca. $40 \mathrm{~m}$. The area of Mercury Passage is ca. $195 \mathrm{~km}^{2}$ and it is bisected by a channel running down its length at ca. 20 to $40 \mathrm{~m}$ depth. The secondary bays within the passage are all shallow, in the vicinity of 5 to $10 \mathrm{~m}$ depth. The substrate within Mercury Passage is generally hard packed sand with dispersed areas of patchy reef, together with sparse seagrass on both the western and eastern shores. The minimum distance between Great Oyster Bay and Mercury Passage is $25 \mathrm{~km}$ and the maximum is $32 \mathrm{~km}$.

A total of 83 Vemco $^{\text {TM }}$ VR2 single channel acoustic receivers (www. vemco.com) were deployed in the study area (Fig. 1). These singlechannel acoustic receivers continuously monitor the environment for presence of a unique, digitally coded transmitter signal and then record the date, time, and identity of tagged animals swimming within the detection range of the unit. The majority of receivers were aligned linearly in 7 separate 'curtains' across bays (Table 1), with the individual receivers in each curtain spaced equidistantly between 711 and $1000 \mathrm{~m}$ apart. Additionally, several isolated receivers were placed on discrete spawning beds. The detection ranges of receivers are highly dependent on the study site conditions and also, within a site, on turbulence, salinity and depth (Finstad et al. 2005). Receivers were placed between 1 and $3 \mathrm{~m}$ from the seafloor by attaching them to a steel pole or rope connected to a concrete mooring, such that they were vertical in the water column. Scuba divers retrieved receivers shallower than $20 \mathrm{~m}$, with those deeper than $20 \mathrm{~m}$ retrieved primarily using Sub Sea Sonics acoustic release mechanisms (www. subseasonics.com) or, in a few instances, horizontal lines attached to the moorings which were snagged with grappling hooks and hauled to the surface. 
Table 1. Receiver curtain specifications. $C^{1}$ indicates a validation that took place with a 30 to $90 \mathrm{~s}$ transmitter; all other validations conducted using fast-pinging validation tags. $\mathrm{H}^{2}$ incomplete due to tag loss part way through the tow

\begin{tabular}{|c|c|c|c|c|c|c|c|c|}
\hline \multirow[t]{2}{*}{ Curtain } & \multirow{2}{*}{$\begin{array}{l}\text { Length } \\
(\mathrm{km})\end{array}$} & \multicolumn{2}{|c|}{ Distance between receivers $(\mathrm{m})$} & \multicolumn{2}{|c|}{ Depth of receivers $(\mathrm{m})$} & \multirow{2}{*}{$\begin{array}{l}\text { Validation dates } \\
\mathrm{d} / \mathrm{mo} / \mathrm{yr}\end{array}$} & \multirow{2}{*}{$\begin{array}{l}\text { Wind speed } \\
\text { (knots) }\end{array}$} & \multirow{2}{*}{$\begin{array}{l}\text { Wind } \\
\text { direction }\end{array}$} \\
\hline & & Mean & Range & Mean & Range & & & \\
\hline A & 5.3 & 908 & $870-917$ & 12 & $8-24$ & $04 / 12 / 2003$ & 5 & $\mathrm{NE}$ \\
\hline B & 6.75 & 856 & $853-869$ & 11 & $10-15$ & $04 / 12 / 2003$ & $5-20$ & $\mathrm{NE}$ \\
\hline $\mathrm{C}$ & 23 & 859 & $825-893$ & 28 & $8-41$ & $25 / 11 / 2003$ & 5 & SE \\
\hline $\mathrm{C}^{1}$ & & & & & & $10 / 09 / 2003$ & 10 & $\mathrm{~N}$ \\
\hline $\mathrm{E}$ & 8 & 828 & 680-1000 & 32 & $5-44$ & $25 / 11 / 2003$ & 5 & SE \\
\hline $\mathrm{F}$ & 3.6 & 750 & $750-751$ & 8 & $4-10$ & 05/01/2004 & 10 & ENE \\
\hline G & 2 & 712 & $711-712$ & 4 & $3-6$ & 05/01/2004 & 10 & ENE \\
\hline $\mathrm{H}$ & 5.75 & 814 & $813-814$ & 27 & $18-31$ & $25 / 11 / 2003$ & 5 & SE \\
\hline $\mathrm{H}^{2}$ & & & & & & 06/10/2003 & 8 & ESE \\
\hline
\end{tabular}

Receiver curtains across Great Oyster Bay (C), and the top (E) and bottom $(\mathrm{H})$ of Mercury Passage, were aligned with the boundaries of the areas closed to commercial squid fishing (Fig. 1). The commercial closure was from 1 September to 30 November 2003 and the majority of the receivers were in place from 24 July 2003 to 7 January 2004. Receivers can only confirm the presence/absence of a particular squid within the receiver's individual detection radius and as such a single line or curtain of receivers cannot differentiate between individuals crossing the line, or alternatively moving close enough to be detected but not crossing through (Heupel et al. 2006). In order to overcome this problem, some studies (e.g. Lacroix et al. 2005) have used 2 complete lines of receivers to form each curtain. Additionally, double lines of receivers may be beneficial if local conditions allow a tagged animal to pass undetected at one curtain, as the subsequent independent curtain would allow further chances to detect the animal's passage out of key areas. Given we had over $50 \mathrm{~km}$ of boundary curtains, there were not sufficient receivers to create complete double lines. Instead, we created partial double lines (hereafter referred to as 'dual' curtains) by adding additional receivers parallel to and ca. $2 \mathrm{~km}$ from the complete curtains on the edges of the line of receivers across Great Oyster Bay (C) and the top of Mercury Passage (E) (Fig. 1). We reasoned that as squid were in these areas to spawn on the shallow seagrass beds, if movement between or out of the broader regions was to occur it would most likely be in the shallower edge regions with closer proximity to the spawning habitats. As squid appear to be in the monitored regions to spawn in shallow areas, if a tagged squid did pass through the middle of either Curtain C across Great Oyster Bay or E across Mercury Passage, thus missing the dual curtains, it is highly likely that it would still be detected as it passed through the curtains across the mouth of the smaller bays within Great Oyster Bay (Curtain A \& B) or Mercury Passage (Curtain F \& G) (Fig. 1), as it is within these shallower bays that the seagrass beds are concentrated.

Validation of detection gaps in receiver curtains. Estimation of any detection gaps within the curtains was important for estimating the probability of squid leaving the closed area boundaries undetected, and was conducted in 3 different ways. The deeper $\mathrm{H}, \mathrm{E}$ and $\mathrm{C}$ curtains were validated by towing a Vemco ${ }^{\mathrm{TM}}$ V16 coded pinger with a transmission interval of $5 \mathrm{~s}$ and a signal strength of $147 \mathrm{db}$ re $1 \mu \mathrm{Pa} @ 1 \mathrm{~m}$ (hereafter referred to as the 'validation tag') along the line of the receivers. The tag was towed on a weighted line ca. $30 \mathrm{~m}$ behind the $22 \mathrm{~m}$ research vessel RV 'Challenger', with a crane boom used to trail the line $4 \mathrm{~m}$ outboard of the vessel to reduce transmission interference created by the wake and propeller wash. Towing speed was ca. 4 knots and the tag depth ranged from 2 to $4 \mathrm{~m}$ below the surface. Multiple cruises on the RV 'Challenger' were planned for validation of the receiver detection ranges; however, the validation tag was snagged and lost part way through the first validation attempt (Curtain $\mathrm{H}$ ). Immediately after the validation tag was initially lost, a Vemco ${ }^{\mathrm{TM}}$ V9SC-2H coded pinger with a signal strength of $147 \mathrm{db}$ re $1 \mu \mathrm{Pa} @ 1 \mathrm{~m}$ and a random delay of between 30 and $90 \mathrm{~s}$ (as used to tag squid, see 'Acoustic transmitters and tagging' below) was towed by RV 'Challenger', at 4 knots from east to west across the entire Curtain C. A second validation tag with the same specifications as the previous V16 tag subsequently arrived in time for a single validation of each curtain. In terms of execution, all 3 curtains were validated successfully, although achieving a constant speed and towing direction was difficult for some of the receivers located close to shore; this was reflected in the data as poor coverage of curtain-edge receivers. RV 'Challenger' sometimes also had to alter course to avoid shallow reefs.

The shallower Curtain A, B, F and G receivers were validated from smaller vessels. A GPS was used to navigate directly over each receiver and to a point deter- 
mined as halfway between 2 receivers. At each of these locations a validation tag was lowered for between 1 and 2 min. Due to prevailing weather conditions and some shallow reef areas, on occasion the boat engine was left running and the bubbles generated by the engine may have dampened the acoustic signal strength. This method only confirms signal detection directly on, or half-way between adjacent receivers. An additional 'validation' was also achieved by examination of instances where 2 adjacent receivers detected a particular squid acoustic transmitter at the same time. This was able to identify receiver pairs where, at least when conditions were good, there were no detection gaps in the curtains.

Acoustic transmitters and tagging. The acoustic transmitters used to tag calamary were Vemco ${ }^{\mathrm{TM}}$ V9SC$2 \mathrm{H}$ coded pingers (formerly designated as V8SC-2H, $30 \mathrm{~mm}$ in length, $9 \mathrm{~mm}$ in diameter, $3.1 \mathrm{~g}$ in water). These transmit a unique sequence of pings at a frequency of $69 \mathrm{kHz}$ for the duration of battery life, estimated at $120 \mathrm{~d}$ from the date of activation. The pinging sequence is repeated after a random delay of between 30 and $90 \mathrm{~s}$; the random delay is to minimize any chance of signal collision if many tagged animals are transmitting to the same receiver at the same time. Transmitters were activated by soldering 2 small activation wires together, tested with a Vemco ${ }^{\mathrm{TM}}$ VR60 acoustic receiver, and then deployed on calamary within a few days of activation.

Calamary were caught using squid jigs and hand lines from small research vessels and placed gently into a purpose-built tagging cradle. The transmitters were secured to the inside of the ventral mantle via a fine needle attached to the transmitter with 2 part epoxy glue during the activation process. The needle pierced the thickness of the mantle and was secured on the outside of the calamary by a silicon washer and metal crimp (see O'Dor et al. 1994). Calamary were also injected in the base of the arms with 1 to $2 \mathrm{ml}$ of tetracycline dissolved to saturation in seawater $\left(6 \mathrm{mg} \mathrm{ml}^{-1}\right)$ to assist with wound healing, and a numbered t-bar tag with a phone number was attached to the dorsal mantle. The mantle length (ML) was measured to the nearest $5 \mathrm{~mm}$ and the sex determined by observation of the reproductive organs through the semi-transparent mantle. The entire tagging process took ca. $60 \mathrm{~s}$. All tagged calamary were observed to swim off immediately with a strong jetting action.

A total of 59 sexually mature calamary were tagged within the Great Oyster Bay and Mercury Passage areas; females ranged in size from 180 to $395 \mathrm{~mm} \mathrm{ML}$ and males from 210 to $470 \mathrm{~mm} \mathrm{ML;} 16$ calamary were tagged and released prior to the commencement of the 3 mo closed season, with the remainder tagged throughout the closed season until mid November
(Figs. 2 \& 3). Calamary were not tagged all at once, or all at the beginning of the closed season, as we had at that stage no information about the duration of individual spawning. Tag and release locations were distributed along the eastern shore of Great Oyster Bay and both the eastern and western shores of Mercury Passage. Tagging was attempted on the western shore of Great Oyster Bay on several occasions; however, calamary were never captured in that region. We made concerted efforts to ensure tag returns from commercial fishers after the fishery had re-opened. All known currently active commercial calamary fishers were contacted by telephone and the local fishing community was made aware of the tags and rewards for return by advertisements in television, print media and posters.

Analyses. Data files were downloaded from the receivers as text files and then collated in a Microsoft Access database. Individual movement tracks were plotted using the animal movement extension within ArcView (www.absc.usgs.gov/glba/gistools/). No statistical tests were performed due to the spatial autocorrelation of the data. Activity patterns were inferred by the number of visit events (see Stark et al. 2005). The descriptive measurements of time, distance and speed of movements were estimated based on an assumed straight line vector between 2 receivers. Time was recorded as the period between the last detection at one receiver and the first detection at the next nonadjacent receiver (Stark et al. 2005). Distance was the metric distance between 2 receivers (not adjusted for listening radius) and speed was calculated as the distance divided by the time taken to travel between Points $a$ and $b$. As both travel time and travel distance were assumed to be a straight vector between $a$ and $b$ the estimated speed values are not necessarily the maximum speeds attained by Sepioteuthis australis.

\section{RESULTS}

\section{Validation of receiver detection ranges}

Data was not collected from 5 of the 83 receivers due to receivers being lost off moorings or due to problems in downloading; an additional 2 receivers flooded part way through deployment. Each curtain was examined for detection gaps at least once (see Table 1). The V9SC-2H tag towed across Curtain C was detected on all retrieved receivers at least once (including 2 flooded receivers) and in $66 \%$ of cases the tag was detected at least 3 times or more. There was complete and continuous detection of the V16 validation tag across $74 \%$ of Curtain C. Gaps in continuous detection 
were due to 2 flooded receivers $(\mathrm{C} 11 \& \mathrm{C} 16)$ and where the vessel stopped, drifted slightly, and started towing again at C16/C17 (no detection at C17). Using the same method, there was $100 \%$ coverage of Curtain E with no gaps detected, although the vessel could not validate the receiver closest to either end of the curtain. The dual curtain on the Maria Island side had $90 \%$ coverage and for the dual curtain on the mainland side the 2 seaward receivers overlapped, but the receiver closest to shore was not validated due to its proximity to shore. Curtain $\mathrm{H}$ was also validated by towing the validation tag behind RV 'Challenger' in a similar manner to Curtains C \& E, although only $38 \%$ coverage was detected by Curtain $\mathrm{H}$ (note that $\mathrm{H} 1$ was lost, so there was no coverage from this receiver). However, during the initial validation, which was incomplete due to tag loss, there was overlap in tag detection between receivers $\mathrm{H} 4$ \& $\mathrm{H} 6$ and $\mathrm{H} 4$ \& $\mathrm{H} 5$, and the detection ranges appear wider than in the later complete validation. The distances between adjacent

Tag no.

$\mathrm{ML}(\mathrm{mm})$

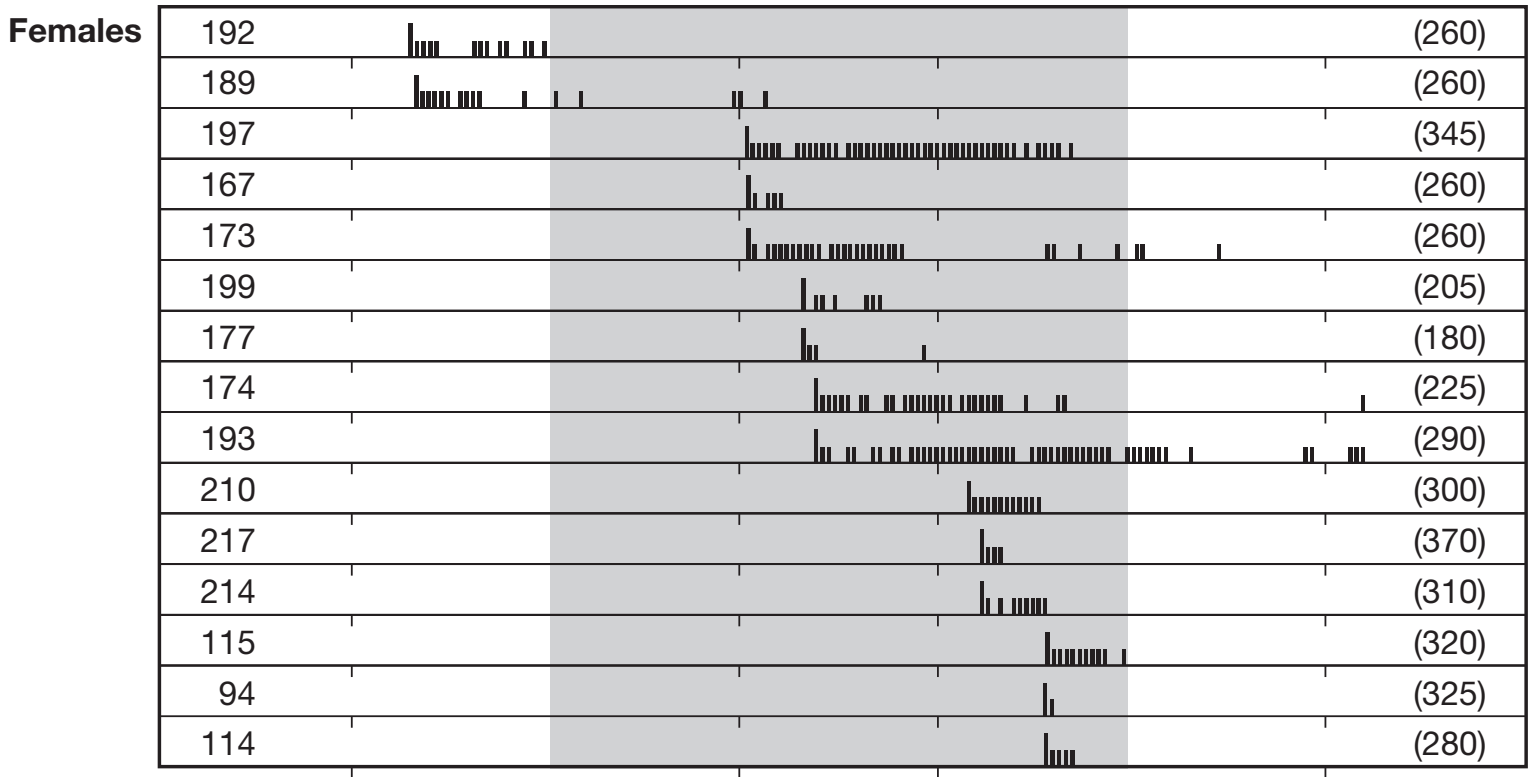

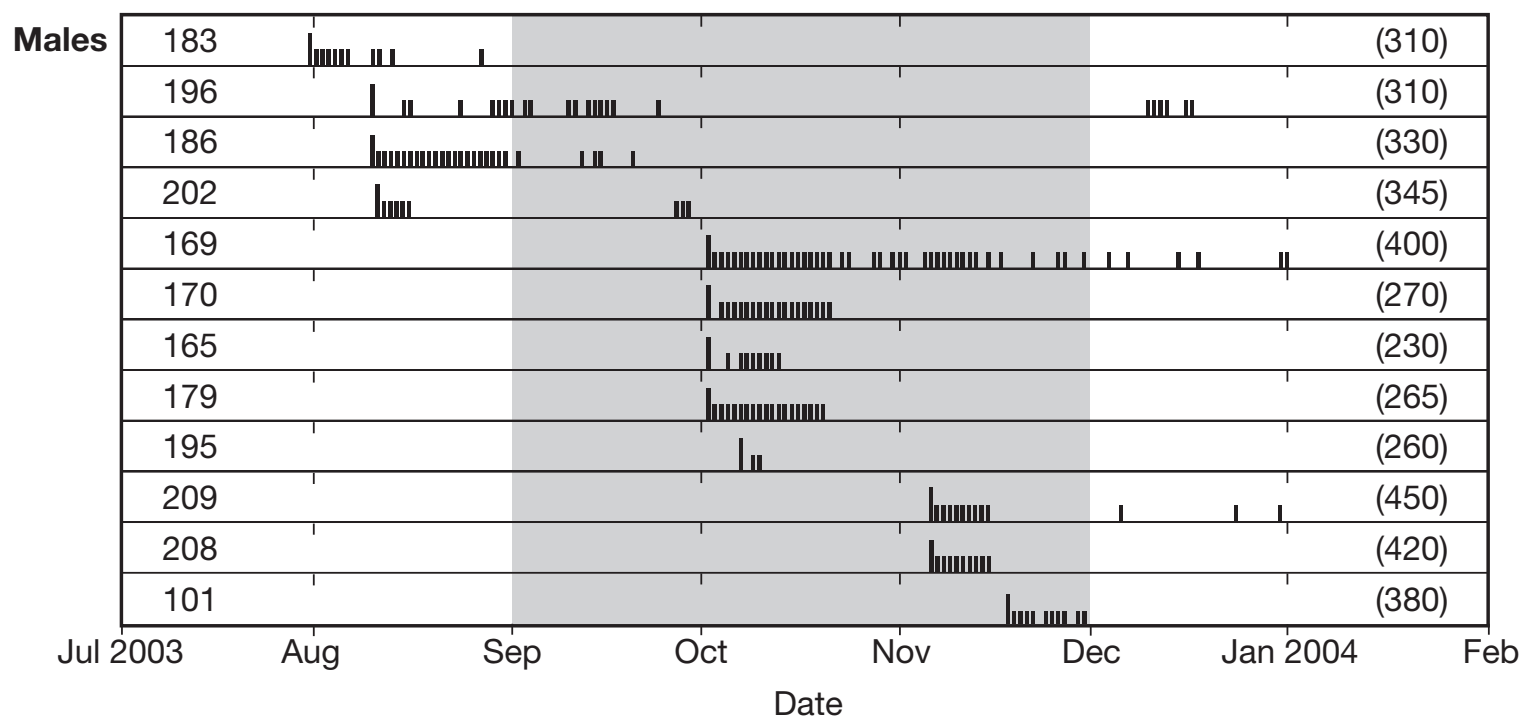

Fig. 2. Sepioteuthis australis. Detection summary for transmitters deployed in Great Oyster Bay; larger spike at beginning shows deployment date; transmitters not subsequently detected on any receivers not shown. Gaps in between adjacent tick marks indicate periods where an individual was not detected. Grey: commercial fishing closure. Mantle length of each tagged calamary is given on right hand side in parentheses 
Tag no.

$\mathrm{ML}(\mathrm{mm})$

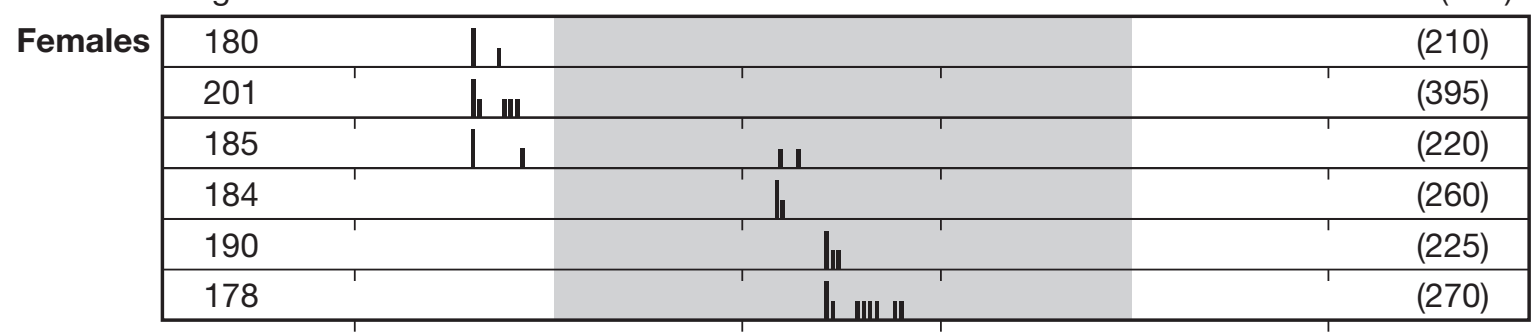

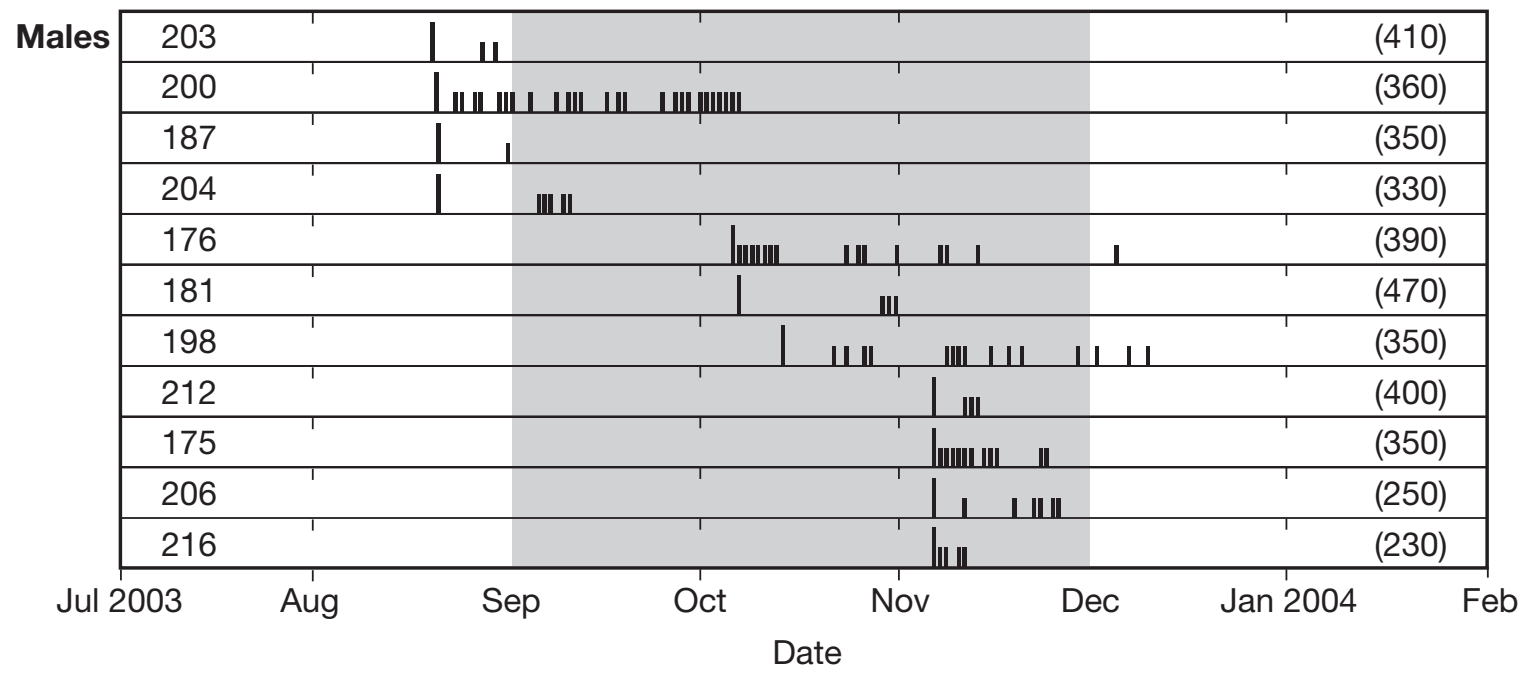

Fig. 3. Sepioteuthis australis. Detection summary for transmitters deployed in Mercury Passage; see Fig. 2 for description

receivers, depth of receivers and prevailing weather conditions were all within similar ranges for Curtains $\mathrm{E}$ \& H. A subsequent survey of these sites with a VR60 to take background biological noise readings revealed that locations of receivers along Curtain $\mathrm{H}$ generally had background noise levels twice as high as locations for receivers along Curtain E.

The drop point validation techniques used for the shallow curtains revealed only 1 detection gap in Curtain A, between A4 and A5. The drop point validation of Curtain B was conducted on the same day, yet wind speed and sea surface height had picked up significantly and although the tag was detected at each receiver, only one pair of adjacent receivers both detected the validation tag at the middle point. For both curtains F and $G$, although the tag was detected at each receiver it was not detected at the middle point of adjacent receivers. However, tagged squid were detected at the shallow curtains (A, B, F \& G) simultaneously on adjacent receivers for 360 visits spread over 42 separate days. This occurred between all adjacent receiver pairs except A1/A2, indicating that there was frequently sufficient overlap between most shallow curtain receivers to detect squid passing through.

\section{Transmitters and calamary movement}

It is assumed that tagging did not alter the behaviour, survivorship or predation risk of calamary. Three acoustically tagged squid were recaptured, one 2 mo after tagging, and all were in good health, supporting this assumption. Overall, $78 \%$ of all tagged calamary (46 individuals) were subsequently detected on receivers with a combined total of 77251 separate detections, 65098 in Great Oyster Bay and 12153 in Mercury Passage. These separate detections translated into 3605 discrete visit events from squid in Great Oyster Bay and 415 from squid in Mercury Passage. Only $10 \%$ (3 individuals) of the Great Oyster Bay tagged calamary eluded detection and these were all males. Most of the undetected tagged calamary were from the Mercury Passage region, with $41 \%$ (12 individuals) of those calamary undetected. There was no significant difference in size between calamary recorded or not recorded on any receivers for females (263 mm ML \pm $68 \mathrm{SD}$ detected; $236 \mathrm{~mm} \mathrm{ML} \pm 39 \mathrm{SD}$ undetected), or males (353 mm ML $\pm 68 \mathrm{SD}$ detected; $298 \mathrm{~mm} \mathrm{ML} \pm$ 77 SD undetected) in Mercury Passage. Release date or location did not seem to have any impact on whether tagged squid in Mercury Passage were detected or not. 


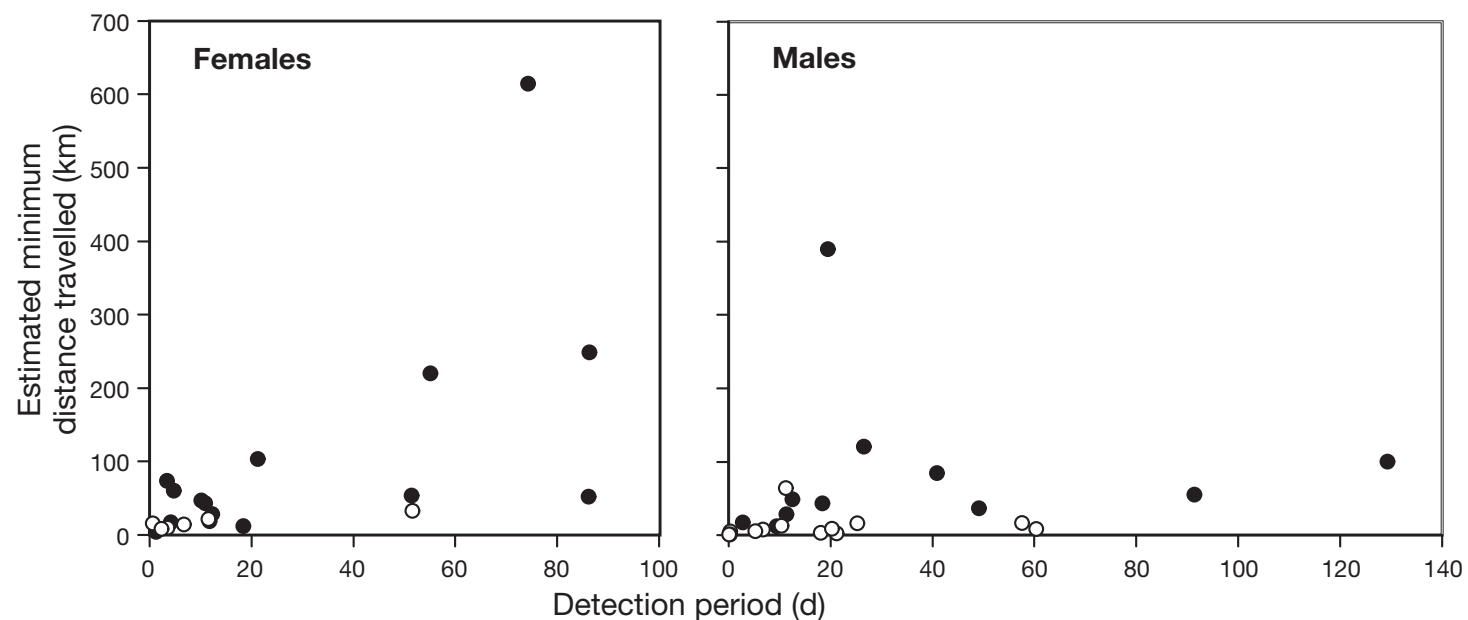

Fig. 4. Sepioteuthis australis. Total detection period and minimum distance traveled. •: Great Oyster Bay; O: Mercury Passage

All of the undetected males were released on the same day; however, they were released in 3 different locations and on both western and eastern shores. Additionally, 4 detected males were tagged and released at the same locations and times.

Transmitters were usually first detected at the receiver closest to the release site and there were between 3 and 9301 detections per transmitter, with each individual recorded on between 1 and 51 separate days. The total duration over which individuals were detected ranged from 1 to $129 \mathrm{~d}$ (9 d longer than the estimated battery life) and 4 transmitters were still active in the few days prior to removal of the VR2 network (Figs. 2 \& 3). Of all the transmitters detected throughout the study, only 6 had $<10$ separate detections.

Minimum distance traveled and speed of movement

Adding up the distance between receivers visited in sequence gave an indication of the total minimum distances squid would have traveled over their respective detection durations. It was estimated that squid of both sexes were commonly covering a minimum distance (all discrete trips combined) of 50 to $100 \mathrm{~km}$, with 1 female traveling at least $614 \mathrm{~km}$ (Fig. 4). There was a positive correlation between total detection period and estimated minimum distance traveled for females from Great Oyster Bay ( $\mathrm{r}=0.618, \mathrm{p}=0.014, \mathrm{n}=15)$ and Mercury Passage ( $r=0.905, p=0.015, n=6)$. Within Great Oyster Bay, females on average traveled $30.8 \mathrm{~km}$ more than males for a given detection period, although this difference between the sexes was not statistically significant ( $p=0.884, F=0.022$, df: 1,23 ). There was no relationship between total detection period and ML for either sex in either region, indicating that initial size of a tagged squid did not affect detection duration. Likewise there was no significant relationship between ML and estimated minimum distance traveled, although for both sexes all distances $>100 \mathrm{~km}$ were traveled by squid of an intermediate size (220 to $320 \mathrm{~mm} \mathrm{ML).}$

Females from Great Oyster Bay made many shorter trips compared with males that made fewer but longer trips ( $\mathrm{p}=0.002, F=9.627$, df 1,148). Out of 150 discrete trips for squid tagged in Great Oyster Bay, most trips $(89 \%)$ were $<4 \mathrm{~km}$. The longest distance traveled in 1 trip was $28.9 \mathrm{~km}$ by a $310 \mathrm{~mm} \mathrm{ML}$ male, and the maximum distance in 1 trip for a female was $12.0 \mathrm{~km}$. Squid reached speeds of up to $0.64 \mathrm{~ms}^{-1}$ and although there was variability in the speeds of travel, particularly for longer trips, the vast majority of trips were between 0.02 and $0.14 \mathrm{~ms}^{-1}$. Mantle specific speeds of travel for each sector ranged from $0.01 \mathrm{ML} \mathrm{s}^{-1}$ to $2.44 \mathrm{ML} \mathrm{s}^{-1}$, and there was a strong power relationship between distance traveled and speed in $\mathrm{ML} \mathrm{s}^{-1}$ (Fig. 5, $r^{2}=0.77, p<0.001$, df: 1,148). Distances traveled by squid in discrete trips in Mercury Passage were very similar; the longest trip was $22.3 \mathrm{~km}$ for a male and $10.7 \mathrm{~km}$ for a female. There was evidence of squid traveling at faster speeds (up to $1.0 \mathrm{~ms}^{-1}$ ) in Mercury Passage. Mantle specific speeds of travel in Mercury Passage were comparable with those of Great Oyster Bay; the fastest trip recorded was a $1.5 \mathrm{~km}$ trip made at $2.6 \mathrm{ML} \mathrm{s}^{-1}$ by a $230 \mathrm{~mm}$ ML male.

\section{Squid movement around closed area boundaries}

Movement was not detected between the closed areas of Great Oyster Bay and Mercury Passage, despite squid being capable of crossing the 25 to $32 \mathrm{~km}$ gap, with individuals from both areas moving over 


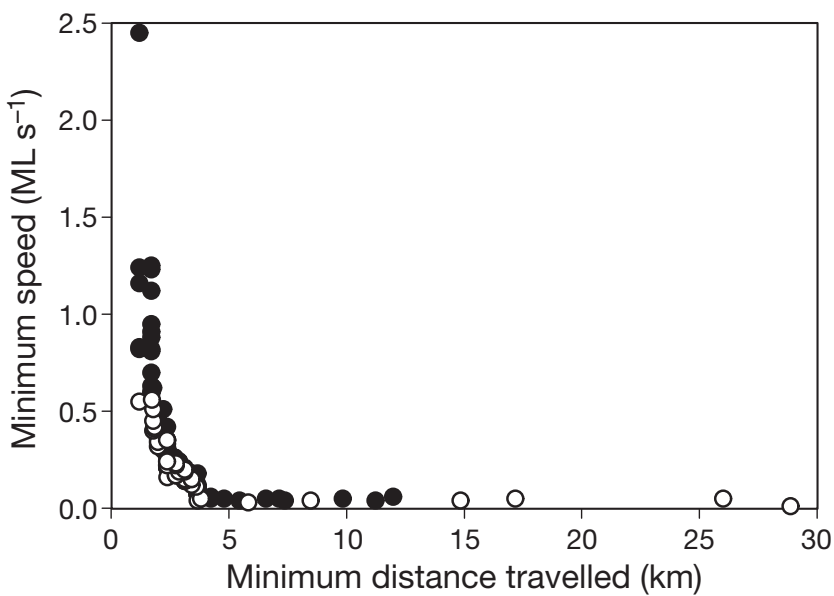

Fig. 5. Sepioteuthis australis. Estimated minimum speeds (mantle lengths $\mathrm{s}^{-1}$ ) of travel in Great Oyster Bay for each sector traveled between non-adjacent receivers. •: females; o: males

large minimum distances and often traveling at fast speeds. Additionally, very little movement in the vicinity of the closed area boundaries (Curtains C, E \& H) was detected in either region. In Great Oyster Bay only 3 squid or $10 \%$ of all tagged animals in that region (2 females and 1 male) were detected on Curtain C, although only 2 of those squid may have left the protection of the closed area as the third squid had its last hit on that curtain after the fishery had re-opened (Table 2). This individual (Transmitter 196) was last detected on several receivers on Curtain $\mathrm{C}$ over a period of $8 \mathrm{~d}$. However, it had previously spent time on both ends of the boundary curtain in August before moving back up towards Coles Bay and spending time at Curtain A.

A total of 6 squid were detected on the Mercury Passage boundary curtains but one of these (Transmitter 178) was only at the double Curtain E, just inside the closed area boundary on the eastern side (E11) for a few hours and then it was detected $8 \mathrm{~h}$ later back at Curtain F. Another squid (Transmitter 181) was detected only at Curtain E although it was last recorded on E11. Transmitter 200 made 3 prior visits to Curtain $\mathrm{E}$ and back to Curtains $\mathrm{F}$ or $\mathrm{G}$ in the 2 wk before its final detection on the middle of Curtain E. Transmitter 185 was only detected on boundary curtains, being first recorded $8 \mathrm{~d}$ after tag and release at the middle of Curtain H (half way down the western shore of Mercury Passage) and then detected for the last time $41 \mathrm{~d}$ later in the middle of Curtain E. Another squid (Transmitter 198) was also detected at Curtain $\mathrm{H}$ but this was after the fishery had re-opened; $19 \mathrm{~d}$ earlier this individual had made a trip to Curtain $\mathrm{H}$ and then returned to Curtain $\mathrm{F}$ before returning to the same receivers at the middle of Curtain $\mathrm{H}$.

Movement and habitat usage within Great Oyster Bay

Squid were detected on all receivers placed on spawning beds (I, J \& K) and all receivers within Curtains A \& B across Coles Bay and Promise Bay, respectively (Fig. 1). However, squid movement was only detected at 8 of 33 receivers within Curtain C (main curtain and 2 smaller double curtains). Activity was detected on the first 4 receivers of the main Curtain $\mathrm{C}$ on the western side and 1 double curtain receiver at that end, as well as 3 receivers on the eastern end of the main curtain, all within close proximity to reef and seagrass areas at the north of Schouten Island (Fig. 1). All Curtain C detections were made by only 1 or 2 individuals per receiver, whilst between 3 and 5 and between 5 and 12 individuals visited the Curtain A \& B receivers, respectively. The receivers visited by the greatest number of individuals were the $2 \mathrm{~J}$ spawning bed receivers (18 individuals), which also recorded the greatest number of detections and visits.

Table 2. Sepioteuthis australis last recorded on the boundary curtains of Great Oyster Bay (Curtain C) and Mercury Passage (Curtains E \& H)

\begin{tabular}{|c|c|c|c|c|c|c|c|}
\hline Transmitter & Sex & Size & $\begin{array}{c}\text { Date and time of } \\
\text { tagging }(\mathrm{d} / \mathrm{mo} / \mathrm{yr} \mathrm{h}: \mathrm{min})\end{array}$ & $\begin{array}{l}\text { Tagging } \\
\text { site }\end{array}$ & $\begin{array}{l}\text { Penultimate } \\
\text { receiver hit }\end{array}$ & $\begin{array}{l}\text { Last } \\
\text { receiver hit }\end{array}$ & $\begin{array}{c}\text { Date and time of } \\
\text { last hit }(\mathrm{d} / \mathrm{mo} / \mathrm{yr} \mathrm{h}: \mathrm{min})\end{array}$ \\
\hline \multicolumn{8}{|c|}{ Great Oyster Bay } \\
\hline 115 & $\mathrm{~F}$ & 320 & 18/11/2003 09:45 & Lodge & $\mathrm{C} 23$ & $\mathrm{C} 22$ & $30 / 11 / 2003$ 05:19 \\
\hline 167 & $\mathrm{~F}$ & 260 & 02/10/2003 11:00 & Williams & B7 & $\mathrm{C} 26$ & 07/10/2003 05:09 \\
\hline $196^{\mathrm{a}}$ & $\mathrm{M}$ & 310 & $10 / 08 / 200310: 55$ & Bryants reef & A6 & C31 & $07 / 12 / 200317: 42$ \\
\hline \multicolumn{8}{|c|}{ Mercury Passage } \\
\hline 201 & $\mathrm{~F}$ & 395 & 19/08/200313:45 & Return point & F2 & E9 & 26/08/2003 08:19 \\
\hline 185 & $\mathrm{~F}$ & 220 & 19/08/2003 15:05 & Earlham & $\mathrm{H} 4$ & E6 & 27/08/2003 05:31 \\
\hline 200 & $\mathrm{M}$ & 360 & $20 / 08 / 2003$ 07:50 & Return point & E6 & E5 & 07/10/2003 14:59 \\
\hline $198^{\mathrm{a}}$ & $\mathrm{M}$ & 350 & $14 / 10 / 2003$ 15:00 & Earlham & F5 & H6 & $11 / 12 / 2003$ 06:09 \\
\hline
\end{tabular}



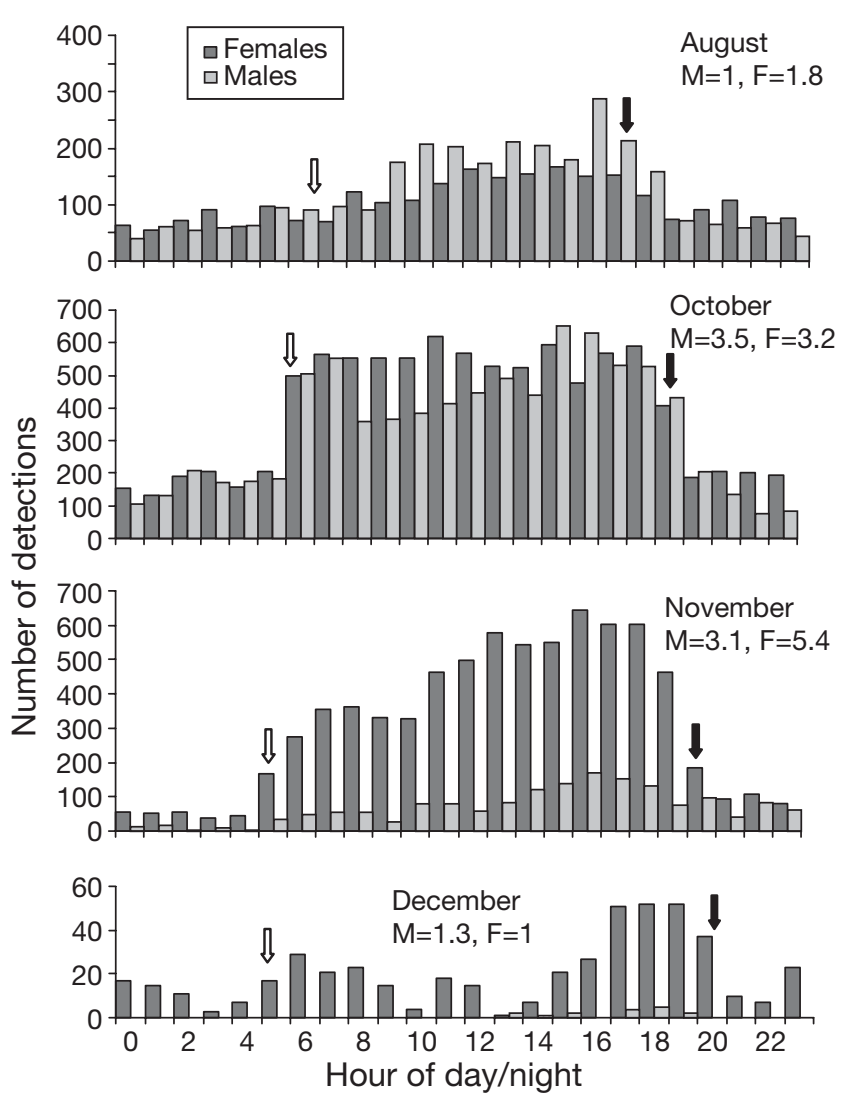

Fig. 6. Sepioteuthis australis. Number of detections by receivers on spawning beds in Promise Bay (J1 \& J2), based on a total of 16 squid and sorted into hourly categories for each sex. $M$ and $F$ : average number of males or females respectively present that month in each hourly block. Note different scale for $y$-axes. Sunrise and sunset indicated by arrows

Detections recorded by Curtain J \& B receivers were pooled into hourly categories for each sex and month to allow examination of any periodicity in squid activity in either area. There was a clear pattern to activity at the $\mathrm{J}$ receivers (located on seagrass) with more detections from both males and females recorded during daylight hours (Fig. 6). The hour of increased detections at the $\mathrm{J}$ receivers corresponds very closely with the onset of sunrise in each month, suggesting that increased daylight is a cue for activity on the spawning grounds. In comparison, there was no clear hourly pattern to the activity recorded at the adjacent deeper-water Curtain B receivers, located over mainly sandy bottom (Fig. 7). Individuals of both sexes also spent much more time on the $\mathrm{J}$ spawning bed compared with Curtain B (Fig. 8), particularly females who also spent almost twice as much time at Curtain B than males did. During the night, males and females were spending similar amounts of time on the spawning beds. However, during the day males spent almost twice as much time at $\mathrm{J}$ compared with females for
August and October, with the sexes spending equal amounts of time in November. Interestingly, of the 8 males that were detected at the $\mathrm{J}$ or $\mathrm{B}$ receivers, only 1 was also detected elsewhere, yet 5 out of 10 females detected at $\mathrm{J}$ or $\mathrm{B}$ were also recorded as moving elsewhere, either into Coles Bay or around Schouten Island (e.g. Fig. 9).

\section{Movement and habitat usage within Mercury Passage}

With 7 tagged females and 5 tagged males undetected by any receivers in Mercury Passage, there was subsequently a much lower level of activity than compared with that reported in Great Oyster Bay; 15 of the 17 detected squid were recorded at Curtain F, although only 5 squid ( 1 female and 4 males) were recorded at Curtain $\mathrm{G}$ just a few km away in the next bay further south. This is probably a function of the substrate differences, as Booming Bay, where Curtain $\mathrm{F}$ crosses, has adequate quantities of seagrass, whereas the other bay (Curtain G) has very little (Mount et al. 2005). In addition, 13 of 16 Curtain E receivers recorded squid activity, although this was the result of only 5 squid: 2 males and 3 females. Only 2 squid were detected at Curtain $\mathrm{H}$ on a total of 3 receivers.
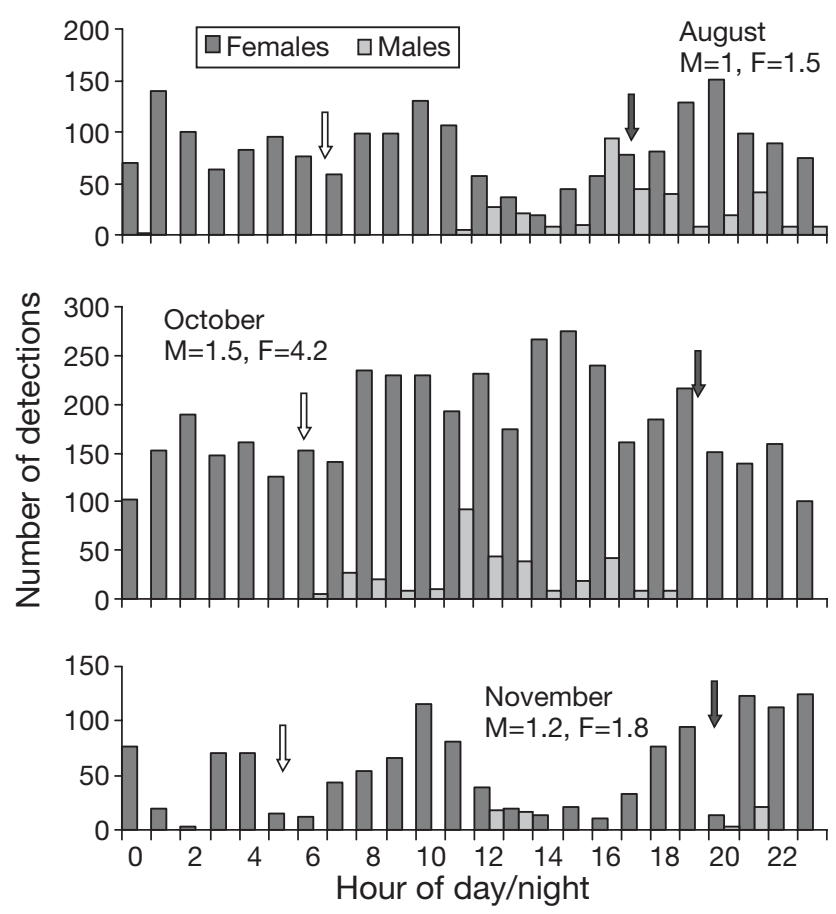

Fig. 7. Sepioteuthis australis. Number of detections by receivers along Curtain B (Promise Bay), based on a total of 17 squid. See Fig. 6 for explanations 


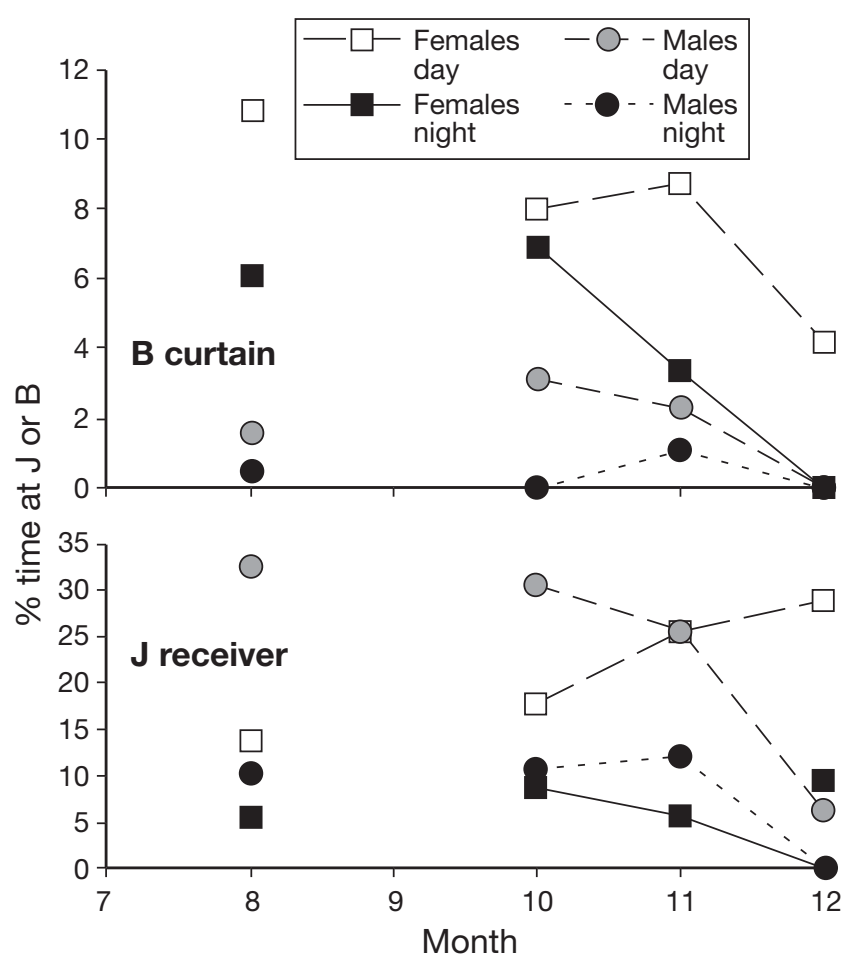

Fig. 8. Average amount of time spent during the day or night at Curtain B or the J receiver pair, by male and female Sepioteuthis australis in each month. Time expressed as \% of total time an individual was detected at $\mathrm{J}$ or B combined. Note different scale for $y$-axes

\section{DISCUSSION}

This study has provided great detail about the sexspecific movements of individual adult squid Sepioteuthis australis throughout an extended spawning season. Up to $90 \%$ (in Great Oyster Bay) of the acoustically tagged individuals were subsequently detected on VR2 receivers, with $30 \%$ recorded for total durations $>1$ mo. Although acoustic telemetry is usually limited to tracking individuals over relatively short durations in comparison to their total lifespan (Elsdon \& Gillanders 2005), we recorded information on the movements of $S$. australis for up to $129 \mathrm{~d}$, representing ca. 20 to $40 \%$ of the estimated total lifespan. Most telemetry studies of cephalopods thus far have been limited to behavioural and/or energetics research using radio acoustic positioning and telemetry (RAPT) systems over small spatial and temporal scales (Sauer et al. 1997, O'Dor et al. 2000). Clearly, acoustic tracking is also a successful research tool by which to explore movement and migration of cephalopods over much larger spatial and temporal scales as demonstrated here, and also by Stark et al. (2005) with Nototodarus gouldi, which were recorded for periods of up to $37 \mathrm{~d}$ using a system of VR2.

We found little evidence of squid leaving the protection of areas closed to commercial fishing during the closure period, and no evidence for large-scale move-
Fig. 9. Sepioteuthis australis. Movements of (a) a $260 \mathrm{~mm}$ ML female (Transmitter 173) and (b) a $400 \mathrm{~mm}$ ML male (Transmitter 169), both tagged and released on the same day and at the same location. The female shows repeated movement between the inshore receivers on the spawning beds and the curtains across Coles Bay and Promise Bay, as well as between the 2 bays. Where lines cross the land, the squid passed undetected through the curtains. The male squid was only detected within Promise Bay, with the majority of movements between the 2 inshore spawning bed receivers. Note that straight lines between 2 receivers do not imply that squid followed a direct path, but merely that the squid was detected at these receivers in sequence
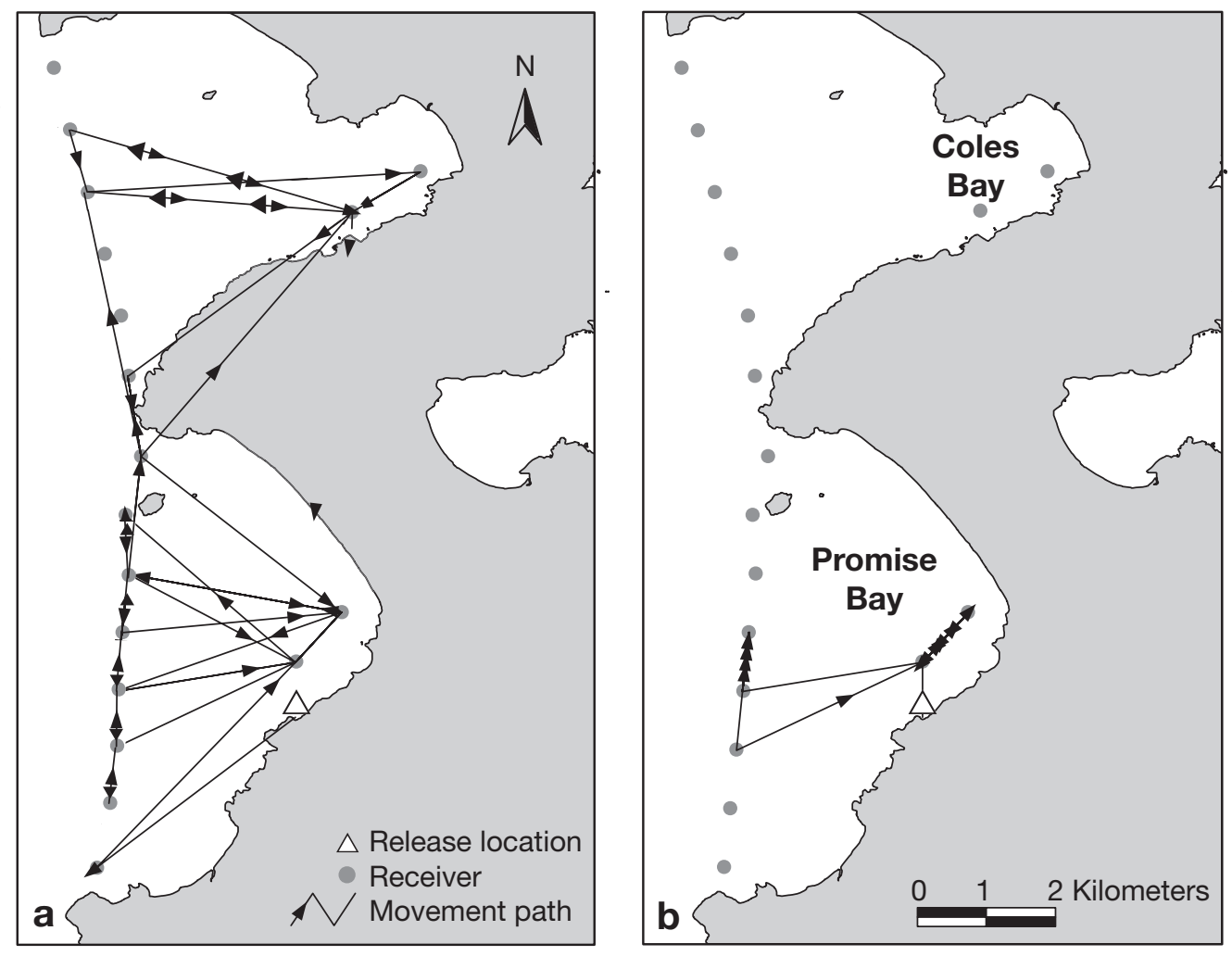
ments between the apparently discrete regions of Great Oyster Bay and Mercury Passage. The results from the VR2 network are also supported by the outcome of a comprehensive t-bar tagging program conducted at the same time and in the same regions. Squid were caught up to $60 \mathrm{~d}$ after t-bar tagging with 174 recaptures from a total of 1770 tagged squid, all recaptured within the same broad region (i.e. Mercury Passage or Great Oyster Bay) where they had been tagged (G. T. Pecl \& S. R. Tracey unpubl. data). This suggests no squid movement between Great Oyster Bay and Mercury Passage during the spawning season, and little or no movement across the boundaries of the closed areas, beyond which commercial fishing (and therefore the opportunity for recapture) was still taking place. Although the present study did not detect any exchange of individuals from one region to another during the spawning phase, such movement could occur in pre-mature individuals, and we are not able to provide information about connectivity between Mercury Passage and Great Oyster Bay. With continued miniaturization of telemetry tags, acoustic tagging may offer a viable method of tagging and tracking very small organisms (Sibert \& Nielsen 2000), although the use of trace elements in hard structures as natural tags may be a better approach for the smallest of animals, e.g. hatchlings.

Although the detection range of receivers is highly variable, both between receivers and locations and also temporally within a location (e.g. Finstad et al. 2005) our confidence in the ability of the VR2 system to detect most boundary movements was high, with the exception of the curtain at the bottom of Mercury Passage (Curtain $\mathrm{H}$ ). The probability of detecting an individual as it passes through a VR2 curtain or gate is a function of VR2 detection radius, which may vary with environmental conditions, minimum/maximum random tag off times, animal swimming speed, and number of animals within range (Heupel et al. 2005). Validation of Curtains C \& E revealed that it was highly likely that we would detect squid movement across those boundaries, and therefore between Mercury Passage and Great Oyster Bay if it occurred. There was a low probability of limited movement out of Mercury Passage towards Great Oyster Bay with 3 of the 29 squid tagged in Mercury Passage having their last hits at the top of Mercury Passage (Curtain E) relatively early on in the spawning season. However, none of these animals were subsequently detected at Curtain $\mathrm{C}$ or any other curtains within Great Oyster Bay, making that scenario rather unlikely. Poor detection coverage of the VR2 curtain at the bottom of Mercury Passage (Curtain H) limited our ability to assess movement across that boundary accurately, so it is possible that squid moved undetected out of the bottom of the passage. Nevertheless, squid activity was still detected on $\mathrm{H}$ receivers, so it would be unlikely that all 12 undetected squid, and other squid that were only detected for a short time in Mercury Passage, were all crossing that curtain without any of them being detected at all. The generally much lower level of activity recorded in Mercury Passage compared with Great Oyster Bay suggests a different behavioural dynamic occurring in that region. This is also suggested by the results of tbar tag study that reported a recapture rate from Great Oyster Bay over twice that of Mercury Passage (G. T. Pecl \& S. R. Tracey unpubl. data). It is also possible that tagged squid in Mercury Passage were subsequently occupying habitats not covered by the VR2, e.g. deeper water in the middle of the passage, where fishers on occasion have reported high catches.

The short life cycle of cephalopods, often unpredictable biomass, and vulnerability to overfishing results in limited management options, constrained by the nature of the fisheries and poor quality of data (Pierce \& Guerra 1994). In addition, although there is growing support for the use of closed areas or seasons in the management of squid fisheries (e.g. Hatfield \& Des Clers 1998, Leos 1998, Moltschaniwskyj et al. 2002), there is limited evidence upon which to assess closed areas as a management tool. Important expectations of closed areas are a reduction in effort as a function of the shortened fishing season, and protection to spawners, particularly females, at the peak of the breeding season (Augustyn \& Roel 1998, Roel et al. 1998). The protection afforded to a squid population by the implementation of a closed area is a function of the temporal and spatial scale of the spawning activities of the individuals that make up that population, in relation to the temporal and spatial scale of the closed area. It is essential to know how long it takes an individual to deposit eggs in order to estimate the proportion of reproductive output protected, and to effectively assess spawning abundance, which may be particularly difficult if the population spawning period exceeds the residency of individuals on the spawning grounds.

Acoustic tracking of a relatively large number of individual spawning squid clearly demonstrated that southern calamary are actively moving over large distances, within a defined area, during an extended individual spawning season. Both males and females, already mature and potentially spawning at the time of capture, were actively moving within the spawning area commonly for periods of $2 \mathrm{mo}$, and up to 3 and 4 mo for females and males, respectively. Monthly SCUBA surveys monitoring egg production around the $\mathrm{J}$ and I inshore spawning bed receivers confirm that squid in the vicinity of these receivers were engaging in mating and spawning behaviour, with the peak in egg deposition occurring in October and November 
(N. Moltschaniwskyj unpubl. data; also see Moltschaniwskyj \& Pecl 2003, Moltschaniwskyj et al. 2002). This provides very strong field-based evidence of an extended spawning period for both male and female individuals, potentially constituting around 20 to $40 \%$ of their lifespan. Captive females of the closely related Sepioteuthis lessoniana may spawn over lengthy durations, with 1 female spawning 11 times over 6 wk at intervals of 1 to $9 \mathrm{~d}$, laying 7780 eggs in total, at a temperature of 20 to $28^{\circ} \mathrm{C}$ (Wada \& Kobayashi 1995). With the estimated lifespan of $S$. lessoniana around 6 mo (Jackson \& Moltschaniwskyj 2002), this spawning period would also constitute ca. $25 \%$ of their lifespan. Likewise, tagged Sepia apama remain in their aggregation area actively laying eggs for up to $6 \mathrm{wk}$ (Hall \& Hanlon 2002). Captive Loligo pealeii can spawn small clutches at short intervals or large clutches several weeks apart over durations of up to $50 \mathrm{~d}$, with a big range in spawning frequency and output between captive females (Maxwell \& Hanlon 2000).

Like most loliginds investigated thus far, Sepioteuthis australis arrive at dawn in the vicinity of the egg beds and probably spawn throughout the day (see Jantzen \& Havenhand 2003) with reproductive activity waning at sunset, as with Loligo opalescens (Forsythe et al. 2004), Loligo vulgaris reynaudii (Sauer et al. 1997), Loligo pealeii, and Sepioteuthis sepioidea (Hanlon \& Messenger 1996). Females may be distributing reproductive effort over many different spawning beds, as they made more frequent but shorter trips in and around Great Oyster Bay after being detected on any of the spawning bed receivers, whereas males made fewer, longer trips. However, once a male was detected on a spawning bed receiver, he was not subsequently detected on any receivers away from spawning beds, only on the spawning bed receiver or those on the adjacent bay, e.g. Curtains A or B. Differential movement patterns between the sexes were also supported by an analysis of CPUE throughout the spawning season. This suggests that the abundance of females on the spawning beds remains constant, whilst that of males increases throughout the period of the closure, plummeting rapidly once commercial fishing recommences, indicating that males accumulated on the spawning grounds whilst females did not (Hibberd \& Pecl in press). The 'choice' between showing site fidelity or moving longer distances can have direct consequences in terms of energetic cost, growth, susceptibility to predation, and mortality (Steingrimsson \& Grant 2003), and it appears that $S$. australis males and females may be utilizing slightly different strategies in this respect.

One of the unexpected results of this study concerns the activity spectra of Sepioteuthis australis. Individuals were not only active and moving long dis- tances on occasion, but their speed of movement was also substantial. Sustained movement between different spawning sites over an extended period of time may be a mechanism to facilitate gene mixing and may also reflect times of active hunting in between periods spent on the spawning grounds. These studies of activity further confirm the 'life-in-the-fast-lane' (Jackson \& O'Dor 2001) life histories generally displayed by squid. All of the speeds estimated in this study are within the maximum speeds described for squid (Stark et al. 2005) suggesting that all detections came from tagged squid, and not from larger predators that had consumed the tagged individuals, which would be expected to travel at faster speeds.

This study reveals how acoustic tracking can be not only a useful ecological and behavioural tool, but also a means to obtain critical information needed for fisheries management. The tagging techniques used were successful for relatively long-term tag retention in this important target species. Squid not only displayed rapid movement, but covered surprisingly long distances during their spawning period, which revealed extended reproductive behaviour and sex-specific characteristics in movement patterns. This study provides an excellent example of how movement data can answer pressing management questions in relation to squid exploitation and subsequent management. We now have a robust data set which suggests that squid stay within a single spawning ground (i.e. Great Oyster Bay), but move between individual seagrass spawning beds (e.g. Coles Bay and Promise Bay) within that broader spawning ground. Therefore, closures of critical spawning regions during times of heightened reproductive activity will achieve the required effect of protecting spawners for the development of necessary reproductive behaviour and allow for egg-laying. The data obtained would have been hard to gather by any other means. We strongly recommend that the strategy of closed bays and regions during times of known peak reproductive activity of Sepioteuthis australis be maintained as a means of maximizing protection of the stock. Clearly, even inshore squid species can be highly mobile during an extended spawning phase, and any assessment of the management benefits of closed areas need to explicitly consider the temporal and spatial scales of the closed area in question.

Acknowledgements. The crew of RV 'Challenger' assisted with the major task of deployment and retrieval of the VR2 network; 12 commercial calamary fishers assisted with squid capture and tagging and TAFI staff and volunteers assisted with tagging and diving including A. Morton, G. Ewing, T. Probst, K. Stark, S. Semmens, and J. Bedelph. Kate Stark provided the visit event macro, A. Hobday and B. Bruce provided access to some CSIRO Marine and Atmospheric Research 
receivers and equipment, M. Ardent provided the Access database for us to modify and J. Lyle provided constructive input, as did N. Moltschaniwskyj, in addition to unpublished data. Many participants in the 2004 AMSA workshop also provided feedback and constructive comment and the suggestions of 4 anonymous reviews greatly improved the final manuscript. This research was supported by ARC (grant number LP0347556, using equipment also purchased under LE0237912), DPIWE, the Tasmanian Recreational Fishery Trust (Fishwise), and the Tasmanian Commercial Calamary Fishers. The procedures used in this study were conducted with ethics approval from UTAS AEC (no. A7272).

\section{LITERATURE CITED}

Arendt MD, Lucy JA, Munroe TA (2001) Seasonal occurrence and site-utilization patterns of adult tautog, Tautoga onitis (Labridae), at man made and natural structures in lower Chesapeake Bay. Fish Bull 99:519-527

Augustyn CJ, Roel BA (1998) Fisheries biology, stock assessment, and management of the chokka squid (Loligo vulgaris reynaudii) in South African waters: an overview. Cal Coop Ocean Fish 39:71-80

Comeau LA, Campana SE, Castonguay M (2002) Automated monitoring of a large-scale cod (Gadus morhua) migration in the open sea. Can J Fish Aquat Sci 59:1845-1850

Egli DP, Babcock RC (2004) Ultrasonic tracking reveals multiple behavioural modes of snapper (Pagrus auratus) in a temperate no-take marine reserve. ICES J Mar Sci 61: $1137-1143$

Elsdon TS, Gillanders BM (2005) Alternative life-history patterns of estuarine fish: barium in otoliths elucidates freshwater residency. Can J Fish Aquat Sci 62:1143-1152

Finstad B, Okland F, Thorstad EB, Bjorn PA, McKinley RS (2005) Migration of hatchery-reared Atlantic salmon and wild anadromous brown trout post-smolts in a Norwegian fjord system. J Fish Biol 66:86-96

Forsythe J, Kangas N, Hanlon RT (2004) Does the Californian market squid (Loligo opalescens) spawn naturally during the day or at night? A note on the successful use of ROVs to obtain basic fisheries biology data. Fish Bull 102: 389-392

Fulton E, Kault D, Mapstone B, Sheaves M (1999) Spawning season influences on commercial catch rates: computer simulations and Plectropomus leopardus, a case in point. Can J Fish Aquat Sci 56:1096-1108

Hall KC, Hanlon RT (2002) Principal features of the mating system of a large spawning aggregation of the giant Australian cuttlefish Sepia apama (Mollusca: Cephalopoda). Mar Biol 140:533-545

Hanlon R (1998) Mating systems and sexual selection in the squid Loligo: how might commercial fishing on spawning squids affect them? Cal Coop Ocean Fish 39:92-100

Hanlon RT, Kangas N, Forsythe JW (2004) Egg-capsule deposition and how behavioural interactions influence spawning rate in the squid Loligo opalescens in Monterey Bay, California. Mar Biol 145:923-930

Hanlon RT, Messenger JB (1996) Cephalopod behaviour. Cambridge University Press, Cambridge

Hatfield E, Des Clers S (1998) Fisheries management and research for Loligo gahi in the Falkland Islands. Cal Coop Ocean Fish 39:81-91

Heupel MR, Simpfendorfer CA, Hueter RE (2004) Estimation of shark home ranges using passive monitoring techniques. Environ Biol Fish 71:135-142

Heupel MR, Simpfendorfer CA, Lowe C (2005) Passive acoustic telemetry technology: current applications and future directions. Mote Tech Rep No. 1066, Mote Marine Laboratory, Sarasota, Florida, p 98. Available at: http:// hdl.handle.nte/2075/85

Heupel MR, Semmens JM, Hobday AJ (2006) Automated acoustic tracking of aquatic animals: scales, design and deployment of listening station arrays. Mar Freshw Res 57:1-13

Jackson GD, Moltschaniwskyj NA (2002) Spatial and temporal variation in growth rates and maturity in the Indo-Pacific squid Sepioteuthis lessoniana (Cephalopoda: Loliginidae). Mar Biol 140:747-754

Jackson GD, O'Dor RK (2001) Time, space and the ecophysiology of squid growth, life in the fast lane. Vie Milieu 51(4):205-215

Jackson GD, Pecl GT (2003) The dynamics of the summer spawning populations of the loliginid squid Sepioteuthis australis in Tasmania, Australia-a conveyor belt of cohorts. ICES J Mar Sci 60:290-296

Jantzen TM, Havenhand JN (2003) Reproductive behaviour in the squid Sepioteuthis australis from South Australia: interactions on the spawning grounds. Biol Bull 204: 305-317

Lacroix GL, Knox D, Stokesbury JW (2005) Survival and behaviour of post-smolt Atlantic salmon in coastal habitat with extreme tides. J Fish Biol 66:485-498

Leos RR (1998) The biological characteristics of the Monterey Bay squid catch and the effect of a two-day-per-week fishing closure. Cal Coop Ocean Fish 39:204-211

Lyle J, Haddon M, Ziegler PE, Tracey SR (2005). Tasmanian scalefish fishery - 2004. Tasmanian Aquaculture and Fisheries Institute, Hobart, Tasmania. Available at: www.utas. edu.au/tafi/PDF_files/FF_Assessment_Rep_2004.pdf

Maxwell MR, Hanlon RT (2000) Female reproductive output in the squid Loligo pealeii: multiple clutches and implications for a spawning strategy. Mar Ecol Prog Ser 199: $159-170$

Moltschaniwskyj NA (1995) Multiple spawning in the tropical squid Photololigo sp.: What is the cost in somatic growth? Mar Biol 124:127-135

Moltschaniwskyj NA, Pecl GT, Lyle J (2002) An assessment of the use of short-term closures to protect spawning southern calamary aggregations from fishing pressure in Tasmania, Australia. Bull Mar Sci 70:501-514

Moltschaniwskyj NA, Pecl GT (2003) Small-scale spatial and temporal patterns of egg production by the temperate loliginid squid Sepioteuthis australis. Mar Biol 142: 509-516

Mount RE, Lucieer VL, Lawler MM, Jordan AR (2005) Final report to the National Heritage Trust. Mapping of estuarine and marine habitats in the southern NRM region, NHT46397 (04/NHTGFS04/102507NHT). Tasmanian Aquaculture and Fisheries Institute, Hobart, Tasmania, Australia. Available at: www.utas.edu.au/tafi/seamap/pdf/ Southern_Estuaries_Final_Report05

O'Dor RK, Hoar JA, Webber DM, Carey FG, Tanaka S, Martins HR, Porteiro FM (1994) Squid (Loligo forbesi) performance and metabolic rates in nature. Mar Freshw Behav Physiol 25:163-177

O'Dor RK, Aitken JP, Babcock RC, Bolden SK, Seino S, Zeller DC, Jackson GD (2000). Using radio-acoustic positioning and telemetry (RAPT) to define and assess marine protected areas (MPAs). In: Sibert JR, Nielsen JL (eds) Electronic tagging and tracking in marine fisheries, Vol. 1. Kluwer Academic Publishers, Dordrecht, p 147-167

Pecl G (2001) Flexible reproductive strategies in tropical and temperate Sepioteuthis squids. Mar Biol 138:93-101 
Pecl GT (2004) The in situ relationships between season of hatching, growth and condition in the southern calamary, Sepioteuthis australis. Mar Freshw Res 55:429-438

Pecl GT, Moltschaniwskyj NA, Tracey SR, Jordan A (2004) Inter-annual plasticity of squid life history and population structure: ecological and management implications. Oecologia 139:515-524

Pierce GJ, Guerra A (1994) Stock assessment methods used for cephalopod fisheries. Fish Res 21:255-285

Roel B, Cochrane K, Butterworth D (1998) Investigation on the effects of different levels of effort and of the closed season in the jig fishery for chokka squid Loligo vulgaris reynaudii. S Afr J Mar Sci 19:501-512

Sauer WH, Roberts MJ, Lipinski MR, Smale MJ, Hanlon RT, Webber DM, O'Dor RK (1997) Choreography of the squid's 'Nuptial Dance'. Biol Bull 192:203-207

Editorial responsibility: Otto Kinne (Editor-in-Chief), Oldendorf/Luhe, Germany
Sibert JR, Nielsen JL (2000) Electronic tagging and tracking in marine fisheries. Proc Symp Tagging and Tracking Marine Fish Electronic Devices. Kluwer, Dordrecht

Stark KE, Jackson GD, Lyle JM (2005) Tracking arrow squid movements with an automated acoustic telemetry system. Mar Ecol Prog Ser 299:167-177

Steingrimsson SO, Grant JWA (2003) Patterns and correlates of movement and site fidelity in individually tagged young-of-the-year Atlantic salmon (Salmo salar). Can J Fish Aquat Sci 60:193-202

Wada Y, Kobayashi T (1995) On an iteroparity of the oval squid Sepioteuthis lessoniana. Nippon Suisan Gakkaishi 61:151-158

Zeller DC (1997) Home range and activity patterns of the coral trout Plectropomus leopardus (Serranidae). Mar Ecol Prog Ser 154:65-77

Submitted: July 7, 2006; Accepted: October 6, 2006 Proofs received from author(s): December 12, 2006 